
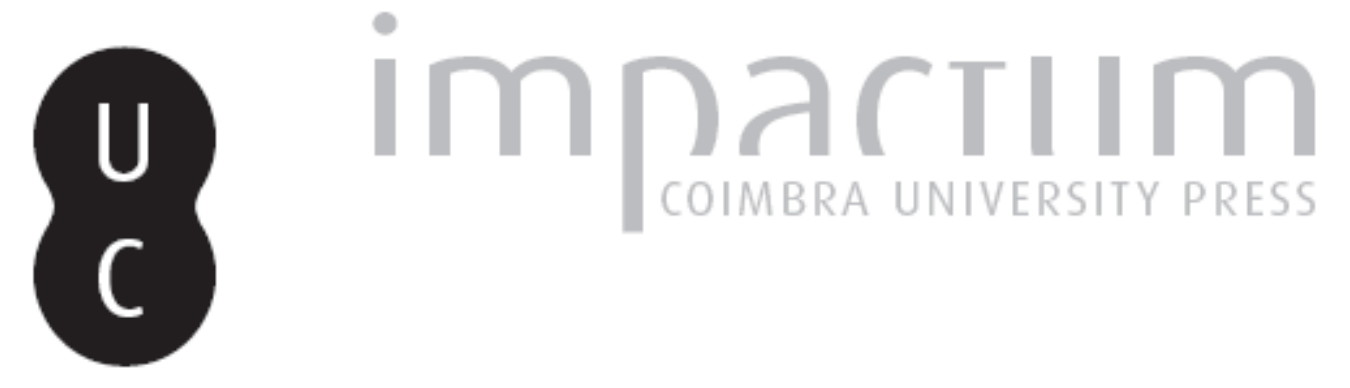

\title{
Coimbra: um novo mapa
}

\section{Autor(es): $\quad$ Costa, Alexandre Alves}

Publicado por: Editorial do Departamento de Arquitectura

URL persistente:

URI:http://hdl.handle.net/10316.2/37467

DOI:

DOI:http://dx.doi.org/10.14195/0874-6168_4_1

Accessed : $\quad$ 26-Apr-2023 14:01:28

A navegação consulta e descarregamento dos títulos inseridos nas Bibliotecas Digitais UC Digitalis, UC Pombalina e UC Impactum, pressupõem a aceitação plena e sem reservas dos Termos e Condições de Uso destas Bibliotecas Digitais, disponíveis em https://digitalis.uc.pt/pt-pt/termos.

Conforme exposto nos referidos Termos e Condições de Uso, o descarregamento de títulos de acesso restrito requer uma licença válida de autorização devendo o utilizador aceder ao(s) documento(s) a partir de um endereço de IP da instituição detentora da supramencionada licença.

Ao utilizador é apenas permitido o descarregamento para uso pessoal, pelo que o emprego do(s) título(s) descarregado(s) para outro fim, designadamente comercial, carece de autorização do respetivo autor ou editor da obra.

Na medida em que todas as obras da UC Digitalis se encontram protegidas pelo Código do Direito de Autor e Direitos Conexos e demais legislação aplicável, toda a cópia, parcial ou total, deste documento, nos casos em que é legalmente admitida, deverá conter ou fazer-se acompanhar por este aviso.

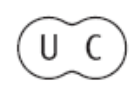




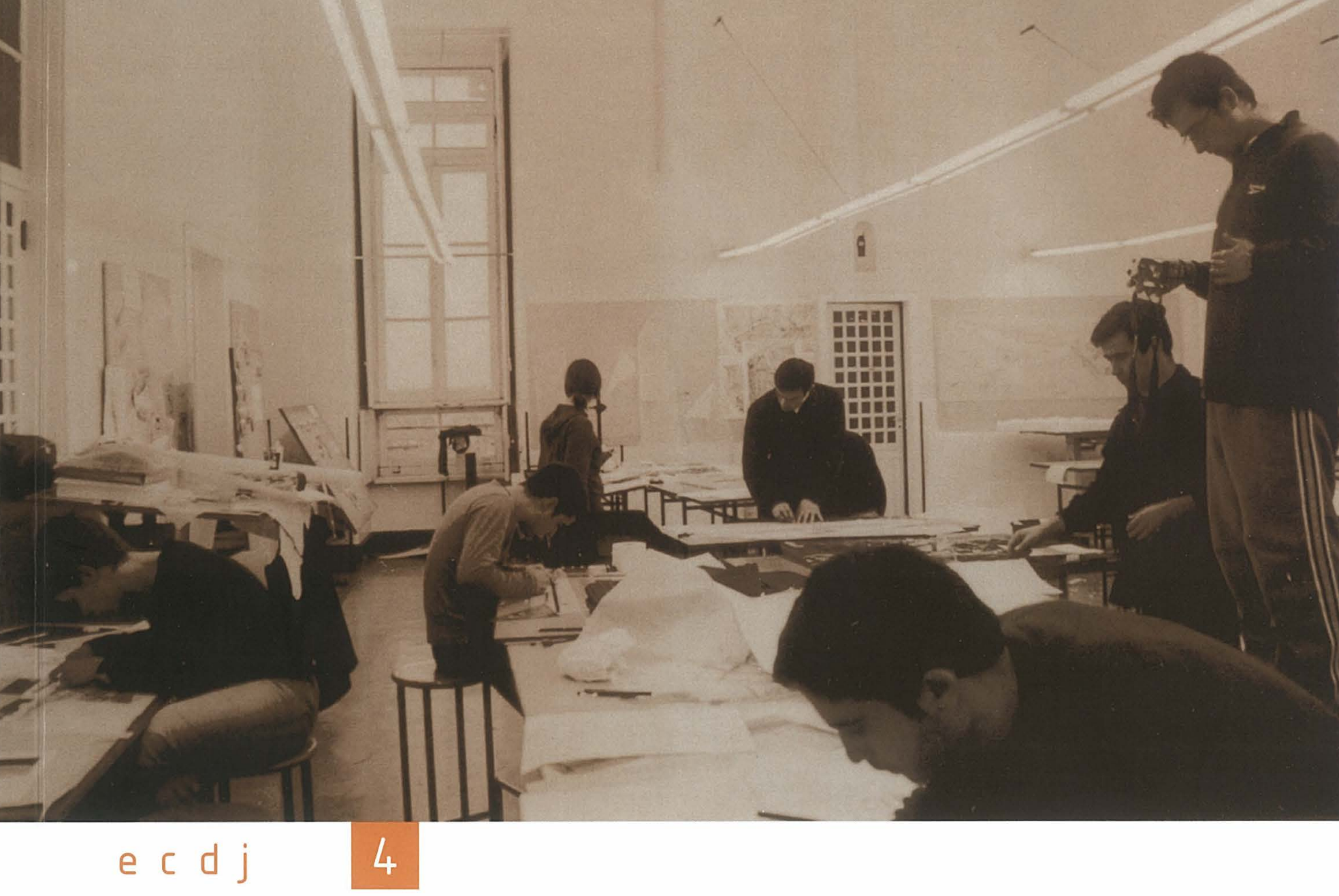

fctuc | departamento de arquitectura

coimbra: um novomapa

manuel gallego

workshop internacional de arquitectura

manuel solà-morales

manuel graça dias

гаúl hestnes fеггеiга

sergio fernandez

álvarosiza entrevista

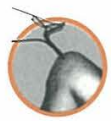


coimbra: um novo mapa alexandre alves costa

Aparece perdida e arruinada, a desfazer-se sem razão e a refazer-se híbrida e desconexa. Coimbra, pensei, estará submetida a algum insondável designio divino? Será que um "non" de Deus bloqueia o seu projecto? Ouvi, pareceu-me que do seu lado, uma gargalhada sinistra: que projecto? Tentei responder, defender da desonra, da vergonha, a cidade,

a universidade e só me vinha à memória o discurso oficial, de autosuficiencia municipal proferido na abertura do "workshop". Não respondi. 


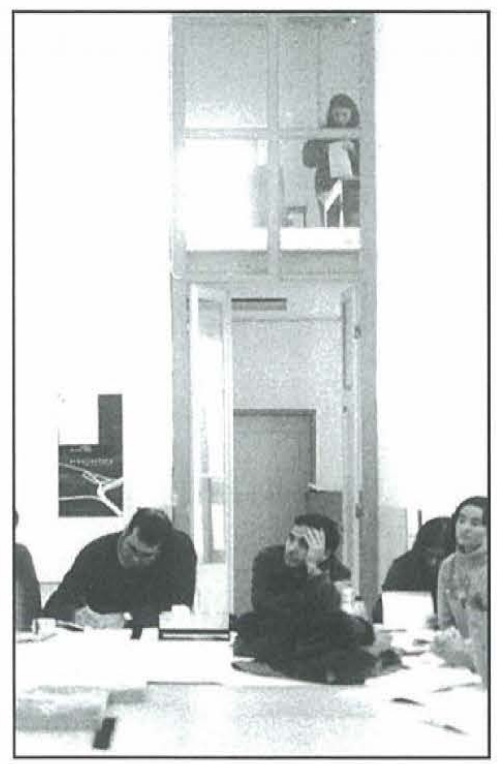

Sabemos que a cidade consolidada não necessita de mais planos, no sentido da tradição moderna, mas sim do que os urbanistas reformistas italianos designaram por "terceira geração de planos", feitos, não para expansão, mas para consolidação e ordenamento da cidade existente. A cidade consolidada necessita de tratamento, manutenção, requalificação. Necessita de se abrir a novos usos e de se densificar com eles. Necessita de uma observação cuidada, de uma intervenção culta e contemporânea que aceite a diversidade,

lendo e preservando a sua unidade, que salvaguarde a sua lindíssima história, visível e oculta, que resista à demolição e à tendência geral para uma passiva aceitação da cultura da suburbanidade, transposta a pretexto de garantia de vitalidade.

> Sabemos, também, que a história dos espaços urbanos está apontada, com o necessário rigor científico, e muitas contribuições recentes têm sido dadas em estudos que aprofundam aspectos mais operativos, no sentido de constituírem fundamentos indispensáveis para uma intervenção projectual estruturada na realidade, vinculada a uma história mais rica e complexa do que uma simples e impressionista leitura epidérmica pode fornecer. 
> Alguma investigação desenvolvida, ou em curso, no âmbito da área disciplinar da arquitectura, fornece elementos seguramente novos, seja a nível da compreensão dos processos de gestão municipal que, na diversidade política das suas conformações, se relacionaram com os interesses privados em constante mutação, seja a um nível mais formal, na construção, perenidade ou ruptura das tipologias que construíram a cidade. Se acrescentarmos a estes estudos todos os que se têm desenvolvido noutras áreas do conhecimento, da economia à sociologia, da geografia à urbanística, pode dizer-se que a cidade tem já uma base de investigação que não deixa pretextos para intervenções, diríamos, menos cultivadas, como tantas que tem comprometido seriamente a sua integridade essencial, o seu carácter único, a sua imensa riqueza patrimonial. E não é só de destruição total ou substituição inútil de conjuntos por outros de maior ou menor qualidade, falamos, também, do imenso perigo que na prática uma certa ideologia patrimonial fachadista representa.

> Temos consciência que tomar este conhecimento como matéria de projecto é, hoje, um dever cívico, mais, portanto, do que uma obrigação ou necessidade puramente disciplinar e que ele constitui, para além de um estímulo, um enriquecimento notável de qualquer projecto de intervenção.

"Temos consciência que tomar este conhecimento como matéria de projecto é, hoje, um dever cívico."

> Mas a cidade não é a cidade consolidada, é toda a cidade, a consolidada, o subúrbio e o resto.

> Como construir e onde o futuro?

> A consciência dos nossos limites, de tempo e de cultura, e dos perigos e vantagens que acarreta o pragmatismo, não pode impedir, no entanto, a formulação de desejos de construção de uma cidade melhor.

> E, com algum mau senso, como diz o Manuel Graça Dias, poderemos construir cenários plausíveis ou irreais para apoiarmos o desejo e a invenção e influenciar o futuro.

Precisamos de encher a paisagem, agradecida por ser cidade. Precisamos de quem goste de cidades, de quem seja portador de uma radical modernidade, visionária, caminho aberto a desejosas utopias, mundos vislumbrados.

> É indispensável vencer esta batalha de conformidades várias, desejos pequenos de moradias de quatro frentes, carros enfiados debaixo de chorões constantes. A cidade é o lugar da democracia, plurifuncional, pluricultural, pluriracial, interclassista, o lugar mais vário. A cidade tem que diminuir, encolher, escolher a densidade.

> Mas, sendo assim, como entrar no corrigir por al fora, mesmo planeado, agradando aqui ou ali, agradecendo mais à frente: algum transporte público, algum traçado viário peatonal, algum hiper de rara felicidade e muita conversa sobre tempos livres, cultura, desporto, escolas. Como se podem desejar teatros, cinemas, bares restaurantes, sex-shops, marisqueiras, antiquários, livrarias ou alfarrabistas abertos toda a noite? 

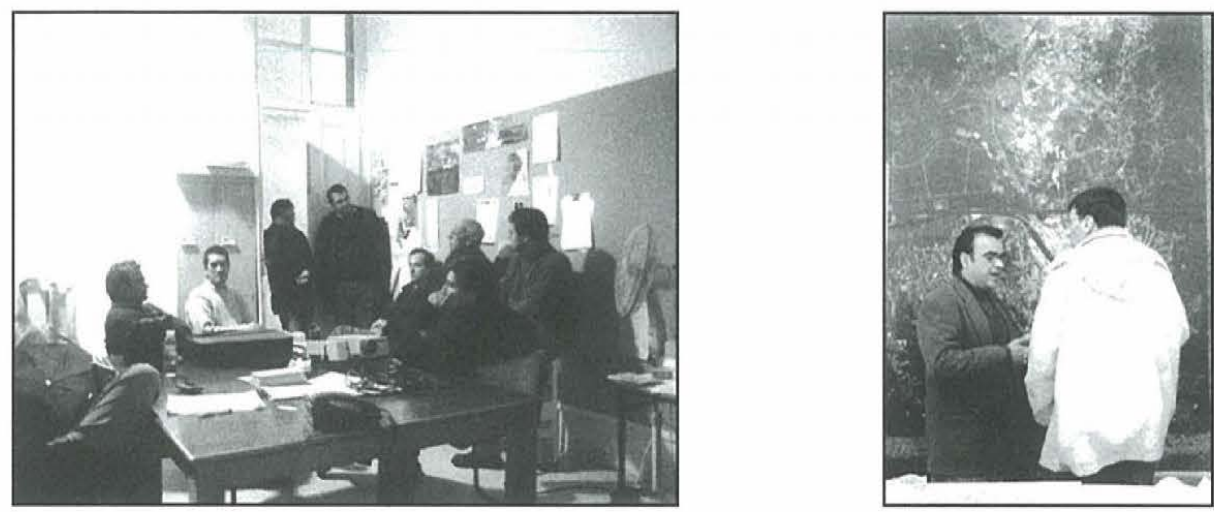

> De facto, a grande criação do nosso tempo, a que vivemos antes do século XXI, é o subúrbio.

> Ele tende a espalhar por todo o território o seu modelo uniforme. De início encosta-se ao que chamávamos cidade, de seguida avança sobre ela destruindo-a para se construir e, noutro sentido, segue as estruturas viárias da rentabilização que o mercado comanda.

> O subúrbio não tem sítio, auto-definiu-se quando o homem deixou de fazer cidades, na dúvida que the ficou quando o campo se deixou de definir como seu opositor. O subúrbio não tem inventores porque nunca foi aceite como não-cidade, outra-coisa que nunca se quis programar.

> O que significa que a cidade consolidada, ela mesmo, está em perigo de ser engolida pela lógica do que Koolhaas chama a cidade genérica e desaparecer na sua voragem ocupacional. Ou então, salvaguardada por ser património, como cenário artificial e ridículo, esvaziado de gente e conteúdo, para venda de postais ilustrados que multiplicam a sua imagem morta, representações de uma realidade falsa ou inexistente a fazer esquecer a verdadeira que não queremos ver, nem viver e não serve para vender programas turísticos.

> Lisboa tem a mesma área do que Barcelona e um terço dos seus habitantes. Será que o diminuto aumento populacional em Coimbra tem alguma relação directa com o enorme surto de construção nos últimos 10 anos? Os construtores t t’êm que construir novo e abandonar o velho. Ganham com isso e as finanças locais também.

> O subúrbio nasceu desenhado pela especulação. A sua grande qualidade é a mestiçagem de gentes, ofícios e memórias que poderão fazer florescer uma nova cultura a que provisoriamente 
chamamos de suburbana, se a liberdade der origem a uma moral que transforme a violência em solidariedade, que trabalhe a selva para que se possam semear as novas searas.

Ali não existe uma memória colectiva, vive-se na construção de consensos de circunstância.

> O que é possível é dar forma àqueles consensos, formas provisórias de uma nova arquitectura concebida entre a circunstância do real a que temos de responder com maior ou menor senso e o tremendo universo do desconhecido, onde procuramos terra, sempre a terra que nos prende, para o exercício da nossa liberdade.

> Por isso desenhamos um novo mapa. Partimos da periferia, das áreas chamadas de desenvolvimento, fomos às saídas. Fomos buscando sinais do urbano sem forma.

> Tínhamos consciência de que a cidade não é apenas consequencia de um projecto que é imposto a uma população indiferente que se molda, passiva, às directrizes dos administradores e dos planificadores. Para além dos planos, a urbanidade é, sobretudo, a sociedade que os cidadãos produzem e as maneiras como a forma urbana é "gasta" pelos usuários.

São estes que, em determinado momento, podem desentender-se - e de facto desentendem-se com certa assiduidade - das directrizes urbanísticas oficiais e constituir formas próprias de territorialização, modalidades sempre efémeras e transversais de pensar e utilizar as engrenagens que fazem possível a cidade. Este trabalho, nunca concluído, da sociedade sobre si mesma é o que produz um estado de ebulição permanente que se desenvolve hostil ou indiferente aos discursos e manobras político-urbanísticas.

> Dito de outro modo, o espaço viário, como o conjunto dos outros sistemas urbanos, é objecto de um duplo discurso. Por um lado, é produto de um desenho urbanístico e arquitectónico politicamente determinado, cuja vontade é orientar a percepção, oferecer sentidos práticos, distribuir valores simbólicos e influenciar as estruturas relacionais dos usuários.

Por outro, pelo contrário, é o discurso deliberadamente incoerente e contraditório da própria sociedade que tem sempre a última palavra sobre, como e em que sentido mover-se fisicamente, na trama proposta pelos projectistas. É o simples peão que reinventa os espaços planeados, os submete aos seus ardis, os usa do seu ponto de vista, impondo os seus percursos a qualquer modelamento prévio, politicamente determinado. Numa palavra, à cidade planificada opõe-se - com indiferença e/ou hostilidade - uma cidade praticada. Esta codificação alternativa que o usuário faz da rua, não gera algo parecido com um continente homogénio e ordenado, mas sim um arquipélago de microestruturas fugazes e cambiantes, descontinuidades mal articulacias, incertas, dubitativas, impossíveis de dominar (M. Delgado, 1999).

> Mas as zonas periféricas das nossas cidades não sendo o produto directo de uma racionalidade política, não são, também, lugares de ordem, regulação, controle e codificação do conjunto não sistematizável das práticas sociais que se desenvolvem no seu seio. São uma espécie de cidades, simultaneamente anteriores ao político - paisagem, topografia, restos vernaculares de modos de produção em desuso, implantações clandestinas - e outras, aparentemente sem a sua medeação -intervenções directas do mais selvagem dos liberalismos. Trata-se de um sistema urbano não codificado e, por isso, de difícil inteligibilidade. 


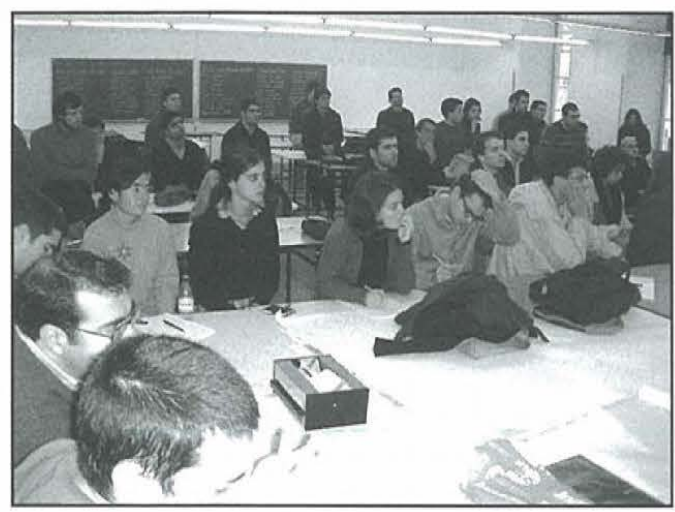

\section{"As zonas periféricas das nossas cidades não sendo o produto directo de uma racionalidade política, não são, também, lugares de ordem."}

> Foi neste terreno aberto que trabalhámos, como se instrumentos de uma nova polis consciente da sua incompetência na hora de integrar e até de entender a maioria das experiências sociais que se desenrolam à sua volta e que se limita a procurar paisagens francas para essa espontaneidade autoregulada em que consiste a vida quotidiana, assegurando que nada ficará excluído do direito ao seu pleno disfrute.

> Corremos riscos, no plano teórico não homogeneizamos posições de princípio.

Aceitamos a diversidade de intenções a partir de uma escolha de sítios e personalidades. O mapa está aí. Tem limites que não fecham, mas explicam bem como seria possível, a partir deles redesenhar o interior, como potenciam uma espécie de força centrípta até ao centro histórico dando-lhe um novo sentido.

> Estes limites, dizemos nós agora, deverão ser os de uma fortaleza indefensável, à mercê de todas as invasões imaginadas e inimagináveis, vulnerável à irupção massiva de desconhecidos, precisamente para que no seu seio todos vejam reconhecido o direito de o serem.

É o espaço público, entre a densidade do construído, que a polis deve manter em boas condições, encenado, decorado, assegurada a sua plena acessibilidade. É aí que se desenvolve a acção pública, num espaço de reuniões baseadas na indiferença pelas diferenças - que não perante as desigualdades - e no contrato implícito de ajuda mútua entre solitários que nem se conhecem. Proscénio em que se transubstânciam os princípios que possiblitam a cidade democrática - a cidadania, o civismo e a civilidade - e remetem para o conjunto de direitos e deveres do cidadão. 